Institute for Research on Poverty

Discussion Paper no. 1130-97

\title{
Patterns of Child Support Compliance in Wisconsin
}

\author{
Daniel R. Meyer \\ School of Social Work and Institute for Research on Poverty \\ University of Wisconsin-Madison \\ E-mail address: dmeyer.ssc.wisc.edu \\ Judi Bartfeld \\ School of Social Work and Institute for Research on Poverty \\ University of Wisconsin-Madison
}

April 1997

The Institute for Research on Poverty provided partial funding for this research through the U.S. Department of Health and Human Services, Office of the Assistant Secretary for Planning and Evaluation. The data were collected under a contract between the Institute for Research on Poverty and the Wisconsin Department of Health and Social Services. Opinions expressed are those of the authors and not necessarily those of the sponsoring institutions.

IRP publications (discussion papers, special reports, and the newsletter Focus) are now available electronically. The IRP Web Site can be accessed at the following address: http://www.ssc.wisc.edu/IRP/ 


\begin{abstract}
This paper examines five-year compliance patterns among Wisconsin child support cases that came to court in 1986-88. We find only limited support for the common assumption that compliance with child support orders declines over time: the average percent paid is about .65 during each of the first five years. The most predominant trend is an increasing polarization into groups of nonpayers and full payers. Although we find considerable stability from year to year among nonpayers and full payers, there is considerable change over the course of five years. Compliance during the first year provides some indication of long-term compliance, but about half of fathers change their compliance rate over the period. We find important differences between divorced and nonmarital fathers, differences that are more pronounced than are apparent from a single year of data. Policy implications are discussed and further research is suggested.
\end{abstract}




\section{Patterns of Child Support Compliance in Wisconsin}

Children living in single-parent families are quite vulnerable economically, with about half living in poverty (U.S. Bureau of the Census 1996). This economic insecurity, coupled with the increasing numbers of such children, has triggered considerable interest in the effectiveness of the child support system.

Low compliance with existing child support obligations is widely acknowledged as problematic by both researchers and policymakers. Nationally, approximately one-half of resident parents with child support orders received the full amount due in 1991, one-fourth received partial payments, and onefourth received nothing (U.S. Bureau of the Census 1995); low annual compliance has also been documented in a variety of local and state-level studies (e.g., Bartfeld and Meyer 1994; Meyer and Bartfeld 1996; Peters et al. 1993). Accordingly, numerous policy initiatives over the past two decades have attempted to increase compliance rates. Such initiatives include intercepting income tax refunds of noncomplying nonresident parents, placing liens on property of delinquent obligors, and routinely withholding child support from the wages of parents with support orders. The most recent initiatives were part of the Personal Responsibility and Work Opportunities Reconciliation Act of 1996, which requires states to have legislation in place to rescind driver's licenses and professional licenses when nonresident parents become delinquent in their payments.

Despite the consensus that child support compliance is inadequate, existing knowledge about long-term compliance is surprisingly limited. We know little about how aggregate compliance rates change between the early and later years of an order, and more importantly, we know little about how compliance changes from year to year at the individual level or how annual compliance compares to compliance over the longer term. Such information is critical both in defining the problem of low child support compliance and in designing appropriate interventions. This paper begins to fill these gaps by 
presenting data on aggregate and micro-level patterns of compliance with child support orders in Wisconsin.

\section{THEORY AND LITERATURE REVIEW}

Theoretical models of child support compliance typically posit that compliance is affected by the nonresident parent's ability to pay, by the economic needs of the resident parent, by the strength of the ties between the nonresident parent and his/her ex-partner and children, and by the stringency of the enforcement system; these models have been substantiated to varying degrees by empirical work examining compliance at a particular point in time relative to the support order (see, for example, Meyer and Bartfeld 1996; Peters et al. 1993).

This general model has potential implications for trends in compliance over the life of a case.

Prior work has shown that the nonresident parent's ability to pay typically increases over time, especially among paternity cases (Meyer 1995; Phillips and Garfinkel 1993), which could lead to increased compliance over time. The availability of a range of enforcement strategies that can be used when noncompliance is detected also suggests that compliance may increase over the life of a case. On the other hand, the nonresident parent's contact with his or her children typically decreases over time: about half of nonresident separated or divorced fathers who have been separated for more than ten years see their child once a year or less, compared to only 13 percent of those separated for two years or less (Seltzer 1991). This decline in the strength of the nonresident parent-child relationship may lead to decreases in payments over time. Furthermore, increases over time in the rate of (re)marriage among both resident and nonresident parents may lead to decreases in the strength of the ties between households and to decreases in the resident parent's level of economic need, and both factors may contribute to declines in compliance. 
Some research on aggregate patterns of child support payments over time has been conducted using cross-sectional data. One simple and somewhat consistent finding is that child support payments are lower among divorce cases in which more time has elapsed since the separation/divorce (Beller and Graham 1993; Seltzer 1991). For example, 54 percent of fathers of marital children who have been separated for more than ten years paid any child support in the last year, compared to 65 percent of those separated less than three years (Seltzer 1991). Similarly, compliance rates (the amount paid divided by the amount due) are lower among those who have been separated for more years (Garfinkel and Robins 1994). A limitation of this work is that the types of cases that have child support orders are changing over time (Beller and Graham 1993), as are the available remedies for noncompliance, suggesting that apparent differences between short-term and longer-term compliance may be confounded by cohort effects.

The above research on aggregate compliance patterns tells us little about patterns of compliance at the case level. A recent study uses case-level longitudinal data to examine child support compliance over a two-and-one-half year period. Peters et al. (1993) examine divorce cases in two counties in California, interviewing the parties within six months of the divorce petition (time 1), then again one and two years later (time 2 and time 3). They find substantial changes in compliance between time 2 and time 3. For example, of the 32 nonresident parents who paid no child support at time 2 , about half were still nonpayers at time 3 , about one-fourth had become partial payers, and about one-fourth had become full payers. Similarly, of the 151 full payers at time 2, two-thirds were still full payers at time 3, with the remaining cases evenly divided between zero payers and partial payers. Peters et al. conclude that "although average compliance declines over time, there is considerable mobility in both directions" (p. 726). This research is an important start to an examination of case-level changes in child support compliance over time, although sample sizes are small and the time period fairly short. 
In this paper, we build on prior work in several ways. First, we use longitudinal data to look at aggregate compliance rates over a five-year period. By using longitudinal instead of cross-sectional data, we eliminate possible cohort effects. Second, we look at year-to-year compliance changes at the case level over five years, a period which is twice as long as that available in prior research. Third, we classify cases with regard to their compliance trajectory over the five-year period. This provides a richer understanding of the current state of child support compliance than has been available from existing annual estimates. Fourth, we examine the relationship between initial compliance and long-term compliance. Finally, we pay particular attention to differences in compliance patterns between nonmarital and divorce cases.

\section{DATA}

The data for this study are from the Wisconsin Court Records Database (WCRD). These data, drawn from the court records of child support cases in twenty Wisconsin counties, were collected by the Institute for Research on Poverty (IRP) to examine the effects of several state-level child support reforms. (For a detailed discussion of the data and sampling procedures, see Brown, Roan, and Marshall 1994). Because nearly all child support payments in Wisconsin are required to be made through the court, the court case record almost always includes data on both support orders and payments, allowing us to construct annual measures of orders, payments, and compliance rates.

For this research, we examine divorce and paternity (nonmarital) cases coming to court between July 1986 and June 1988. These cases are followed until 1993-1994, with the exact ending date varying according to the timing of data collection. We limit our analysis to cases with five years of payment data; fewer years may result when eligible children age out, orders are cancelled (for instance, if the parties reconcile), or orders occur too late in our time-frame to allow for five years of follow-up data. We select a subset of these cases, eliminating three types of cases: cases in which private payments were allowed (3 
percent of the cases); cases in which the effective amount of the child support order is unknown (about one-third of the cases, primarily those in which the order is explicitly linked to the income of the obligor); and cases in which the mother is supposed to pay child support (because these cases may have different compliance patterns and there are too few-approximately 2 percent of the sample — to analyze separately). Our final sample includes 512 cases. The results we present have been weighted to reflect the total number of cases eligible for child support in these counties during this time period. During the time period in which the cases in our sample initially came to court, immediate withholding of child support was mandatory in 18 of the 20 counties.

Findings from Wisconsin may not be completely generalizable to other states. Some data show that the child support system in Wisconsin is more effective than that of many other states: for example, Wisconsin collected \$6.09 in child support for each dollar of administrative expenditure in 1995, compared to $\$ 3.60$ nationally (U.S. House of Representatives 1996). This suggests that the percentage of cases with full payment may be higher in Wisconsin than in other states. Further, this sample does not include Milwaukee County, the major urban area in Wisconsin, because the WCRD includes very few Milwaukee cases with five years of data. Thus, the findings may not be generalized to large urban areas. (However, analyses not reported here indicate that four-year compliance patterns in Milwaukee are quite similar to those found in our twenty-county sample.) The WCRD is used because no national dataset has comparable longitudinal information on compliance with child support orders.

\section{Defining Compliance}

The key outcome measure in these analyses is the annual compliance rate, by which we mean the amount of payment divided by the amount of the obligation. While we define compliance on an annual basis, support is almost always owed and payed more frequently, typically ranging from weekly to monthly. In the WCRD, orders and payments are aggregated at the month level. By focusing on annual rather than shorter-term compliance, we reduce measurement error in order amounts, which may arise 
from computing monthly order amounts from weekly or biweekly orders, as well as measurement error in payments, which may stem from payments being credited slightly later than the actual payment date.

In most of our analyses, we classify cases as nonpayment, partial payment, or full payment. We define the latter as paying at least 90 percent of the obligation, in order to account for potential measurement error as discussed above. We also present information on mean compliance. When payments exceed orders, we code compliance as 100 percent.

\section{RESULTS}

\section{$\underline{\text { Annual Compliance Rates }}$}

We begin by presenting mean annual compliance rates during the first five years following the initial child support order. We also show the proportion of cases with nonpayment, partial payment, and full payment during each year.

As Table 1 illustrates, the mean compliance rate remains quite stable over the first five years, in contrast to the common assumption that compliance declines over time. For the sample as a whole, compliance is .67 during the first year and .64 during the fifth year. However, the stability in the compliance rate masks changes in compliance patterns over the five-year period, with fathers becoming increasingly likely either to pay in full or drop out altogether. During the first year, 15 percent of fathers made no payment, 36 percent paid in part, and 49 percent paid in full. By the fifth year, the share of nonpayers rises to 24 percent, full payers increase to 54 percent, and partial payers fall to 22 percent.

Paternity and divorce cases show somewhat different patterns. Paternity cases exhibit a small but steady decrease in mean compliance rates over the period, from .57 to .50 . The share of nonpayers increases from 20 percent to 33 percent, with a corresponding decline in the share of partial payers and little change in the share of full payers. Among divorce cases, the mean compliance rate is quite stable, fluctuating between .75 and .76 . Similar to paternity cases, divorce cases also show an increase in the 
TABLE 1

Annual Compliance Rates During the First Five Years of Child Support Order

\begin{tabular}{|c|c|c|c|c|c|}
\hline & $\mathrm{N}$ & $\begin{array}{c}\text { Mean } \\
\text { Compliance Rate }\end{array}$ & $\begin{array}{l}\text { Nonpayers } \\
(\% \text { of row }) \\
\end{array}$ & $\begin{array}{c}\text { Partial Payers } \\
(\% \text { of row }) \\
\end{array}$ & $\begin{array}{r}\text { Full Payers } \\
(\% \text { of row }) \\
\end{array}$ \\
\hline \multicolumn{6}{|l|}{ Total $^{\mathrm{a}}$} \\
\hline Year 1 & 512 & .67 & 15 & 36 & 49 \\
\hline Year 2 & & .67 & 17 & 30 & 54 \\
\hline Year 3 & & .67 & 19 & 27 & 54 \\
\hline Year 4 & & .64 & 22 & 24 & 54 \\
\hline Year 5 & & .64 & 24 & 22 & 54 \\
\hline \multicolumn{6}{|l|}{ Paternity $^{\mathrm{b}}$} \\
\hline Year 1 & 189 & .57 & 20 & 43 & 37 \\
\hline Year 2 & & .56 & 23 & 39 & 38 \\
\hline Year 3 & & .55 & 25 & 33 & 42 \\
\hline Year 4 & & $.51^{*}$ & 30 & 32 & 39 \\
\hline Year 5 & & $.50 * *$ & 33 & 31 & 35 \\
\hline \multicolumn{6}{|l|}{ Divorce $^{\mathrm{a}}$} \\
\hline Year 1 & 323 & .75 & 11 & 31 & 58 \\
\hline Year 2 & & .76 & 11 & 22 & 66 \\
\hline Year 3 & & .76 & 13 & 22 & 65 \\
\hline Year 4 & & .75 & 16 & 18 & 66 \\
\hline Year 5 & & .75 & 16 & 16 & 69 \\
\hline
\end{tabular}

${ }^{a}$ The distribution of compliance categories differs by year $(\mathrm{p}<.01)$.

${ }^{b}$ The distribution of compliance categories differs by year $(p<.10)$.

*Significantly different from year $1, \mathrm{p}<.10$.

$* *$ Significantly different from year $1, \mathrm{p}<.05$. 
share of nonpayers, from 11 percent to 16 percent. In contrast to paternity cases, there is also an increase in the share of full payers, from 58 percent to 69 percent.

\section{Case-Level Changes in Compliance}

While aggregate compliance rates remain fairly constant over a five-year period, with nonresident parents becoming increasingly polarized into groups of full payers and nonpayers, these findings do not indicate the extent to which compliance patterns of individual payers change over time. In Table 2, we examine the stability of compliance at the case level. We present a single cross-tabulation of compliance in one year compared to compliance in the next year, with each case contributing four transitions (i.e., year one to year two, year two to year three, etc.) to the total. Results indicate that both nonpayers and full payers show considerable stability from year to year: 79 percent of nonpayers in a given year remain nonpayers the next year, while 84 percent of full payers remain full payers. On the other hand, only half of partial payers remain in this category the next year, whereas 18 percent become nonpayers and 32 percent become full payers. Finally, there is an extremely low rate of transitions between nonpayment and full payment during consecutive years, with only 2 percent of nonpayers paying in full the following year, and only 1 percent of full payers failing to pay anything the next year. The four years which contribute to these results all exhibit similar transition rates, indicating that year-to-year stability in compliance does not vary systematically over the first four years. For instance, the stability among nonpayers ranges from 74 percent to 84 percent in years one through four, with no time trend, while the stability in full payers ranges from 82 percent to 87 percent.

The last two rows of each panel document differences between paternity and divorce cases in year-to-year compliance transitions. The rate of change from nonpayment to both partial and full payment is similar for the two case types. However, paternity fathers who are partial payers in a given year are significantly more likely to pay nothing the following year than are divorced fathers ( 21 versus 14 percent) and less likely than divorced fathers to pay in full (28 versus 37 percent). In addition, 
TABLE 2

Relationship between Compliance Rates during Consecutive Years

\begin{tabular}{|c|c|c|c|c|}
\hline \multirow[b]{2}{*}{ Year $n$} & \multirow[b]{2}{*}{$\mathrm{N}$} & \multicolumn{3}{|c|}{ Year $n+1$} \\
\hline & & $\begin{array}{c}\text { None } \\
\text { (\% of row) }\end{array}$ & $\begin{array}{c}\text { Partial } \\
\text { (\% of row) }\end{array}$ & $\begin{array}{c}\text { Full } \\
\text { (\% of row) }\end{array}$ \\
\hline \multicolumn{5}{|l|}{ No Payment } \\
\hline All cases & 307 & 79 & 19 & 2 \\
\hline Paternity & 138 & 80 & 19 & 1 \\
\hline Divorce & 169 & 79 & 19 & 2 \\
\hline \multicolumn{5}{|c|}{ Partial Payment ${ }^{\mathrm{a}}$} \\
\hline All cases & 571 & 18 & 50 & 32 \\
\hline Paternity & 276 & 21 & 51 & 28 \\
\hline Divorce & 295 & 14 & 48 & 37 \\
\hline \multicolumn{5}{|c|}{ Full Payment ${ }^{\mathrm{b}}$} \\
\hline All cases & 1170 & 1 & 15 & 84 \\
\hline Paternity & 342 & 1 & 27 & 72 \\
\hline Divorce & 828 & 0 & 9 & 90 \\
\hline
\end{tabular}

${ }^{a}$ The distribution of compliance categories in year $n+1$ differs between paternity and divorce cases $(\mathrm{p}<.05)$.

${ }^{\mathrm{b}}$ The distribution of compliance categories in year $\mathrm{n}+1$ differs between paternity and divorce cases $(\mathrm{p}<.01)$. 
paternity fathers who pay in full are less likely than divorced fathers to remain full payers in the following year (72 versus 90 percent). This greater movement toward partial and nonpayment on the part of nonmarital fathers is consistent with the decrease in aggregate compliance found among the nonmarital sample. We document greater stability among both nonpaying and full-paying divorce cases than Peters et al. (1993), perhaps because their compliance measure is monthly rather than annual.

\section{Long-Term Compliance}

While the above analyses document considerable stability in compliance from year to year, they also indicate that compliance is not static, especially among certain subgroups. For instance, half of partial payers change to a different compliance category in the following year, as do more than onefourth of the nonmarital full payers. This suggests that a single year of compliance data may not be an optimal predictor or measure of long-term compliance and that categorizing payers on the basis of a single year of data may obscure important differences among cases.

We turn now to a longer-term analysis of child support compliance. We begin by counting the number of nonpayment and full payment years over the first five years of each case, with results summarized in Table 3. Note that we are concerned here with total years of nonpayment and full payment, regardless of whether such years are consecutive. Overall, one-third of fathers have at least one year of no payment, including 8 percent who never pay. Nonmarital fathers are significantly more likely to have one or more years of nonpayment than are divorced fathers: 44 percent versus 26 percent. Seventy-two percent of fathers have at least one full payment year, including 29 percent who pay in full during each year. Divorced fathers are more likely to have one or more full payment years than are nonmarital fathers - 80 percent versus 61 percent — and are almost four times as likely to pay in full during every year-43 percent versus 12 percent.

To what extent is initial compliance predictive of future compliance? Table 4 shows the distribution of years of nonpayment and full payment during years 2-5, according to the compliance 
TABLE 3

Compliance During First Five Years of Child Support Order

Total

Paternity

Divorce

Percentage of noncustodial parents with support orders who:

Never pay during first 5 years ${ }^{\mathrm{a}}$

8

11

6

Have at least one nonpayment

year during first 5 years ${ }^{\mathrm{b}}$

34

44

26

Percentage of noncustodial parents with support orders who:

Always pay in full during first 5 years $^{\mathrm{b}}$

Have at least one full payment year during first 5 years ${ }^{\mathrm{b}}$

${ }^{a}$ The percentage in this category differs between paternity and divorce cases $(p<.05)$.

${ }^{b}$ The percentage in this category differs between paternity and divorce cases $(p<.01)$. 
TABLE 4

Years of Nonpayment and Full Payment during Years 2-5 of Child Support Orders, by Initial Compliance Level

\begin{tabular}{|c|c|c|c|c|c|c|c|c|}
\hline & \multirow[b]{2}{*}{$\mathrm{N}$} & \multicolumn{3}{|c|}{ Years of No Payment } & \multicolumn{3}{|c|}{ Years of Full Payment } & \multirow{2}{*}{$\begin{array}{l}\text { Mean Annual } \\
\text { Compliance } \\
\text { Years 2-5 }\end{array}$} \\
\hline & & 0 & $1-3$ & 4 & 0 & $1-3$ & 4 & \\
\hline \multicolumn{9}{|l|}{ Year 1} \\
\hline \multicolumn{9}{|l|}{ Nonpayers ${ }^{\mathrm{a}, \mathrm{b}}$} \\
\hline Total & 63 & 14 & 32 & 54 & 81 & 16 & 2 & .18 \\
\hline Paternity & 27 & 3 & 41 & 56 & 92 & 7 & 1 & .09 \\
\hline Divorce & 36 & 28 & 20 & 52 & 66 & 29 & 5 & .31 \\
\hline \multicolumn{9}{|l|}{ Partial Payers } \\
\hline Total & 177 & 63 & 31 & 7 & 44 & 39 & 17 & .56 \\
\hline Paternity & 82 & 58 & 35 & 7 & 49 & 39 & 12 & .51 \\
\hline Divorce & 95 & 68 & 27 & 6 & 40 & 39 & 23 & .61 \\
\hline \multicolumn{9}{|l|}{ Full Payers $^{\mathrm{c}}$} \\
\hline Total & 272 & 89 & 11 & 0 & 5 & 36 & 60 & .91 \\
\hline Paternity & 80 & 83 & 17 & 0 & 8 & 60 & 32 & .85 \\
\hline Divorce & 192 & 93 & 7 & 0 & 3 & 24 & 74 & .93 \\
\hline
\end{tabular}

${ }^{a}$ The number of no payment years differs between paternity and divorce cases $(p<.01)$.

${ }^{b}$ The number of full payment years differs between paternity and divorce cases $(p<.05)$.

${ }^{\mathrm{c}}$ The number of full payment years differs between paternity and divorce cases $(\mathrm{p}<.01)$. 
category in year 1. Among first-year nonpayers, 86 percent have at least one more year of nonpayment, including 54 percent who remain nonpayers during each of the next four years. Only 19 percent of the first-year nonpayers ever pay in full over the subsequent four years, with a mean compliance rate of .18 during years $2-5$. Divorced fathers who pay nothing in the first year have a better long-term prognosis than do nonmarital fathers. Twenty-eight percent of the divorced fathers have no further years of nonpayment, compared to only 3 percent of the nonmarital fathers. Further, one-third of the initially nonpaying divorced fathers have one or more full payment years, compared to 8 percent of the nonmarital fathers.

Initial partial payers fare somewhat better. Over the next four years, approximately one-third of this group have one or more nonpayment years, more than half have at least one full payment year, and the mean compliance rate over the four years is .56 , more than three times the mean for the initial nonpayers.

Finally, first-year full payers generally fare quite well, with a mean compliance rate of .91 over the next four years. These fathers are unlikely to become nonpayers during the time period considered here; only 17 percent of nonmarital and 7 percent of divorced fathers who initially pay in full have any

years of zero payment. However, such fathers do not necessarily continue to pay in full. Again, divorced fathers have higher rates than nonmarital fathers: while three-quarters of divorced fathers remain full payers during each of the next four years, only one-third of the nonmarital fathers do so.

\section{$\underline{\text { Compliance Patterns }}$}

In the above analysis we were concerned with total years of full payment and nonpayment; we turn now to an analysis that focuses explicitly on trends in compliance. We devise a classification scheme to describe the trajectory of compliance over the five-year period, assigning all fathers to one of six compliance categories: nonpayment, full compliance, increasing compliance, decreasing compliance, some payment, and sporadic payment. The first category includes fathers who make no payments in any 
year, while the second includes those who pay in full each year. The third and fourth categories include those who exhibit a consistent pattern of increasing or decreasing compliance, respectively, over the fiveyear period (defined in more detail below). The fifth category includes fathers who always pay something, do not always pay in full, and demonstrate no clear pattern of increasing or decreasing compliance. Finally, the sixth category includes those who are nonpayers in one or more years, yet who do not demonstrate a pattern of increasing or decreasing compliance. We define "increasers" as fathers who move to a higher compliance category between the first and fifth years (that is, move from no payment to partial or full, or move from partial to full) and whose compliance rate never decreases by more than 10 percentage points from year to year or in total. Likewise, we define "decreasers" as fathers who move to a lower compliance category between the first and fifth years and whose compliance rate never increases by more than 10 percentage points.

The distribution of five-year compliance patterns is shown in Table 5. Slightly more than onethird of the sample exhibit stable compliance patterns over the period, including 8 percent who are nonpayers and 29 percent who are full payers. One-quarter of the cases show a consistent trend in compliance, with 12 percent categorized as increasers and 12 percent as decreasers. Finally, 39 percent of the sample exhibit variable compliance with no clear trend, including one-quarter who always pay something and 14 percent who pay sporadically.

There are substantial differences in long-term compliance patterns between paternity and divorce cases. Paternity cases are more likely to be in the nonpayment (11 percent versus 6 percent), consistent decrease (16 percent versus 9 percent), some payment (32 percent versus 20 percent), or sporadic payment (21 percent versus 8 percent) categories. Divorce cases are almost four times as likely to be in the full payment (43 percent versus 12 percent) and twice as likely to be in the consistent increase (15 percent versus 8 percent) categories. 
TABLE 5

Compliance Patterns Over Five Years

\begin{tabular}{|c|c|c|c|c|c|c|c|}
\hline & \multirow[b]{2}{*}{$\mathrm{N}$} & \multicolumn{6}{|c|}{ Five-Year Compliance } \\
\hline & & None & Full & Increase & Decrease & Some & Sporadic \\
\hline \multicolumn{8}{|l|}{ All Cases $^{\mathrm{a}}$} \\
\hline Total & 512 & 8 & 29 & 12 & 12 & 25 & 14 \\
\hline Paternity & 189 & 11 & 12 & 8 & 16 & 32 & 21 \\
\hline Divorce & 323 & 6 & 43 & 15 & 9 & 20 & 8 \\
\hline \multicolumn{8}{|l|}{ Year 1} \\
\hline$\overline{\text { Nonpayers }}^{\mathrm{a}}$ & 63 & 54 & - & 20 & - & - & 26 \\
\hline Paternity & 27 & 56 & - & 3 & - & - & 41 \\
\hline Divorce & 36 & 52 & - & 43 & - & - & 6 \\
\hline Partial Payers & 177 & - & - & 24 & 13 & 38 & 24 \\
\hline Paternity & 82 & - & - & 17 & 15 & 41 & 27 \\
\hline Divorce & 95 & - & - & 32 & 11 & 36 & 21 \\
\hline Full Payers ${ }^{\mathrm{a}}$ & 272 & - & 60 & - & 15 & 23 & 3 \\
\hline Paternity & 80 & - & 32 & - & 26 & 39 & 4 \\
\hline Divorce & 192 & - & 74 & - & 9 & 15 & 2 \\
\hline
\end{tabular}

${ }^{a}$ The distribution of compliance patterns differs between paternity and divorce cases $(\mathrm{p}<.01)$. 
The next three panels of Table 5 show the distribution of long-term compliance trajectories among fathers initially classified as nonpayers, partial payers, and full payers, respectively. Among initial nonpayers, 54 percent remain nonpayers over the five-year period, 26 percent pay sporadically, and 20 percent show a consistent increase. While the sample sizes are fairly small, a comparison of divorced and nonmarital fathers shows that initially nonpaying divorced fathers are much more likely to show a pattern of consistent increase than are nonmarital fathers ( 43 percent versus 3 percent), and are correspondingly less likely to pay sporadically (41 percent versus 6 percent). Among those divorced fathers whose compliance increases, almost three-quarters increase to full payment (not shown).

Next, we look at cases initially classified as partial payers. Twenty-four percent are increasers over the five-year period, while 13 percent are decreasers. An additional 38 percent make some payment during each year, with no clear trend, while almost one-quarter pay sporadically. Divorced fathers who initially pay in part are about twice as likely as nonmarital fathers to increase to full payment (32 percent versus 17 percent), and are somewhat less likely to be in each of the other long-term compliance categories, although these differences do not reach statistical significance.

The third panel illustrates compliance trajectories among initial full payers. Sixty percent remain full payers over the entire period, while only 15 percent exhibit a decreasing compliance pattern. Decreasing compliance is more prevalent among paternity than divorce cases ( 26 percent versus nine percent), while sporadic payers are infrequent among initial full payers of both case types.

\section{$\underline{\text { Sensitivity Analyses }}$}

We also examined compliance on the quarterly rather than annual level, and our basic conclusions do not change. Quarterly compliance rates are slightly lower, with mean quarterly compliance rates in the .61-.65 range, compared to .64-.67 for the annual rates. Between consecutive quarters, 86 percent of nonpayers remain nonpayers, 40 percent of partial payers remain partial payers, 
and 85 percent of full payers remain full payers, results quite consistent with the annual results reported above.

We also tested the sensitivity of our results to the specific definition of "increasing" and "decreasing" used above. We considered including fathers who always pay in part, but increase their compliance by at least 50 percentage points, in the "increasers" category (with a similar change for decreasers); this would result in reclassification of only five cases. We also considered requiring at least two years of increase (or decrease) to be classified as increasers (or decreasers), which also made only a slight difference in the resulting classifications. Finally, we attempted to classify cases by fitting a regression line to the five years of compliance data for each case, classifying cases as increasers (decreasers) if the slope was positive (negative) and at least twice its standard error. This approach yielded a lower percentage of cases classified as increasers and decreasers.

In all of the above analyses, we focused on compliance rates (that is, payments compared to orders). Because order amounts can change over time, patterns of compliance are not necessarily the same as patterns of child support payments. Over the five-year period, mean payments are quite stable, and median payments increase from $\$ 125$ to $\$ 152$ per month. The order amount changes for about onehalf of the cases in the sample, with increases occurring three times as frequently as decreases.

\section{CONCLUSIONS, IMPLICATIONS, AND FUTURE RESEARCH}

This paper has provided a descriptive analysis of child support compliance patterns over time. We have focused on aggregate compliance rates over the first five years in which support is owed, yearto-year changes in compliance at the micro level, and long-term measures of compliance.

We find that patterns of compliance with child support orders in Wisconsin provide only limited support to the common assumption that compliance rates decline over time. Mean compliance among divorce cases is extremely stable over the first five years, although it does decrease modestly for 
paternity cases. The predominant change over the five-year period is the increasing polarization of cases into groups of nonpayers and full payers, with the increase in full payment concentrated among divorce cases and the increase in nonpayment concentrated among paternity cases.

At the micro level, we find considerable stability from year to year among nonpayers and full payers, with much less stability among partial payers. The greatest stability occurs among full-paying divorced fathers, of whom 90 percent continue to pay in full during the subsequent year. We find virtually no transition (in either direction) between nonpayment and full payment in consecutive years. Despite year-to-year stability, however, there is considerable change in compliance over the course of the five years.

Composite five-year indicators of compliance provide a richer picture than do annual measures. While 15-24 percent of fathers make no payment during a given year, 34 percent have at least one zeropayment year. On the other hand, only 8 percent make no payment during the whole five-year period. Approximately half of fathers pay in full during a given year, 72 percent have at least one full payment year, and only 29 percent pay in full during all years.

Although many fathers change their compliance behavior over the five-year period, compliance during the first year does provide some indication of long-term compliance. Initial nonpayment indicates a high likelihood for compliance problems over the subsequent four years, especially among nonmarital fathers. Despite the array of enforcement tools available, more than half of initial nonpayers—divorced and nonmarital—never pay during the next four years. Initially nonpaying paternity fathers have a particularly poor compliance prognosis, with only 3 percent showing a consistent pattern of increase and a mean compliance rate of only .09 during years 2-5. Initial partial payment is also suggestive of longterm compliance problems, although less severe than among the initial nonpayers. Finally, an important finding is the generally positive outcomes among fathers who pay in full during the first year. This is 
particularly striking among divorced fathers, who have a mean annual compliance rate of .91 during the subsequent four years.

Our analyses document important differences in long-term compliance between divorced and nonmarital fathers, with differences more pronounced than are apparent from single-year data. For instance, divorced fathers are almost four times as likely as nonmarital fathers to pay in full throughout the five-year period; in any given year, divorced fathers are less than twice as likely as are nonmarital fathers to pay in full. Nonmarital fathers with poor compliance are less likely to improve than are divorced fathers, while nonmarital fathers with high compliance are less likely than divorced fathers to maintain that level.

The findings reported here are useful in pinpointing where the key compliance problems presently occur, and have implications for policymakers interested in increasing child support compliance. The consistently lower compliance among nonmarital fathers, especially over the longer term, offers compelling evidence that existing strategies are not sufficient for this group. Clearly, a system in which only 12 percent of nonmarital fathers consistently pay their full orders and 40 percent never pay their full orders, over a five-year period, is not functioning effectively. The persistently poor compliance patterns among this group, coupled with the array of enforcement strategies available during the time period covered by these data, suggest that enforcement alone may be an inadequate strategy; efforts to improve compliance rates may also require focusing on nonresident fathers' ability to pay. The low rate of long-term full payment among those nonmarital fathers who start out as full compliers suggests that efforts to maintain compliance among this group would also be beneficial. On the other hand, existing strategies appear generally effective in maintaining longer-term compliance among those divorced fathers who start out as full payers. For both nonmarital and divorced fathers, initial noncompliance should be viewed as a strong warning of probable long-term compliance problems. 
Our findings raise important issues for future research. In particular, we need further research to identify the mechanisms underlying the compliance patterns documented here. While theoretical models and empirical findings suggest that enforcement, ability to pay, ties between nonresident fathers and children, and economic need of the resident-parent family all contribute to child support compliance, we have little information about how these factors operate in a dynamic context. To what extent do changes in nonresident parents' incomes translate into changes in compliance rates? To what extent do differences in father-child contact account for the lower stability among initially full-paying nonmarital fathers relative to divorced fathers? Do initial compliance habits tend to persist regardless of changes in circumstances? This kind of information has important implications for the design of appropriate interventions.

Finally, it is important to examine the generalizability of our findings to a national sample. The effectiveness of the child support system varies among states, with Wisconsin more effective than the national average in terms of support collected relative to administrative expenses (U.S. House of Representatives, 1996). Further, we have excluded cases with missing information on order amounts, which primarily includes cases in which orders were explicitly indexed to income for one or more years of the period studied. To our knowledge, such orders are not routinely used in other states. 


\section{References}

Bartfeld, J., and Meyer, D. R. 1994. "Are There Really Dead-Beat Dads? The Relationship between Enforcement, Ability to Pay, and Compliance in Nonmarital Child Support Cases." Social Service Review, 68, 219-35.

Beller, A. H., and Graham, J. W. 1993. Small Change: The Economics of Child Support. New Haven, Conn.: Yale University Press.

Brown, P., Roan, C. L., and Marshall, J. L. 1994. "Sample Design, Wisconsin Child Support Demonstration Project." Institute for Research on Poverty, University of Wisconsin-Madison, June.

Garfinkel, I., and Robins, P. K. 1994. "The Relationship between Child Support Enforcement Tools and Child Support Outcomes.” In I. Garfinkel, S. S. McLanahan, \& P. K. Robins (eds.), Child Support and Child Well-Being (pp. 133-71). Washington, D.C.: Urban Institute Press.

Meyer, D. R. 1995. "Supporting Children Born Outside of Marriage: Do Child Support Awards Keep Pace with Changes in Fathers' Incomes?" Social Science Quarterly, 76, 577-93.

Meyer, D. R., and Bartfeld, J. 1996. "Compliance with Child Support Orders in Divorce Cases.” Journal of Marriage and the Family, 58, 201-12.

Peters, H. E., Argys, L. M., Maccoby, E. E., and Mnookin, R. H. 1993. "Enforcing Divorce Settlements: Evidence from Child Support Compliance and Award Modifications." Demography, 30, 719-35.

Phillips, E., and Garfinkel, I. 1993. "Income Growth among Nonresident Fathers: Evidence from Wisconsin.” Demography, 30, 227-41.

Seltzer, J. A. 1991. "Relationships between Fathers and Children Who Live Apart: The Father's Role after Separation." Journal of Marriage and the Family, 53, 79-101.

U. S. Bureau of the Census. 1995. Child Support for Custodial Mothers and Fathers: 1991. Current Population Reports, Series P-60, no. 187. Washington, D.C.: U.S. Government Printing Office.

U.S. Bureau of the Census. 1996. Poverty in the United States: 1995. Current Population Reports, Series P-60, no. 194. Washington, D.C.: U.S. Government Printing Office.

U. S. House of Representatives, Committee on Ways and Means. 1996. 1996 Green Book. Washington, D.C.: U.S. Government Printing Office. 